\title{
308
}

$1 / 31) 68$

IN-1200 June 1968

MASTEh

\section{EFFECTS OF IRRADIATION ON THE SURFACE ACTIVITY} AND DIFFUSIVITY OF HYDROGEN IN STEELS

C. R. Brinkman and J. M. Beeston

\section{IDAHO NUCLEAR CORPORATION NATIONAL REACTOR TESTING STATION IDAHO FALLS, IDAHO}




\section{DISCLAIMER}

This report was prepared as an account of work sponsored by an agency of the United States Government. Neither the United States Government nor any agency Thereof, nor any of their employees, makes any warranty, express or implied, or assumes any legal liability or responsibility for the accuracy, completeness, or usefulness of any information, apparatus, product, or process disclosed, or represents that its use would not infringe privately owned rights. Reference herein to any specific commercial product, process, or service by trade name, trademark, manufacturer, or otherwise does not necessarily constitute or imply its endorsement, recommendation, or favoring by the United States Government or any agency thereof. The views and opinions of authors expressed herein do not necessarily state or reflect those of the United States Government or any agency thereof. 


\section{DISCLAIMER}

Portions of this document may be illegible in electronic image products. Images are produced from the best available original document. 
Printed in the United States of America Available from

Clearinghouse for Federal Scientific and Technical Information National Bureau of Standards, U. S. Department of Commerce Springfield, Virginia 22151

Price: Printed Copy $\$ 3.00$; Microfiche $\$ 0.65$

\section{LEGAL NOTICE}

This report was prepared as an account of Government sponsored work. Neither the United States, nor the Commission, nor any person acting on behalf of the Commission:

A. Makes any warranty or representation, express or implied, with respect to the accuracy, completeness, or usefulness of the information contained in this report, or that the use of any iufurmation, apparatus, method, or process disclosed in this report may not infringe privately owned rights; or

B. Assumes any liabilities with respect to the use of, or for damages resulting from the use of any information, apparatus, method, or process disclosed in this report.

As used in the above, "person acting on behalf of the Commission" includes any employee or contractor of the Commission, or employee of such contractor, to the extent that such employee or contractor of the Commission, or employee of such contractor prepares, disseminates, or provides access to, any information pursuant to his employment or contract with the Commission, or his employment with such contractor. 
. IN-1200

Issued: June 1968

Radiation Effects on Materials

TID-4500

\section{EFFECTS OF IRRADIATION ON THE SURFACE ACTIVITY \\ AND DIFFUSIVITY OF HYDROGEN IN STEELS}

C. R. Brinkman

J. M. Beeston

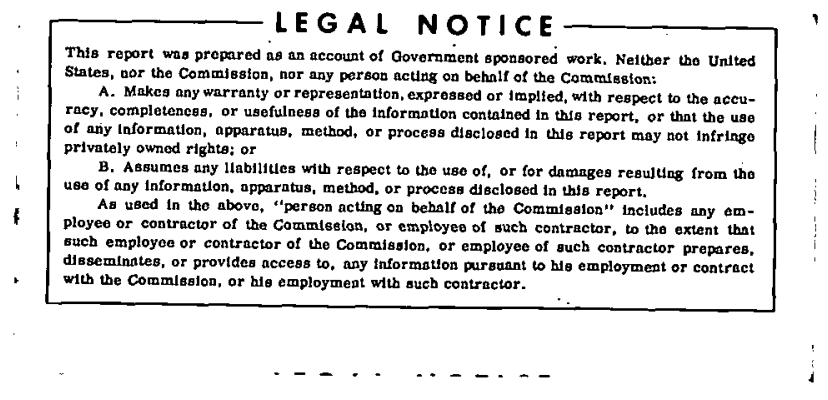

IDAHO NUCLEAR CORPORATION A JOINTLY OWNED SUBSIDIARY OF GENERAL
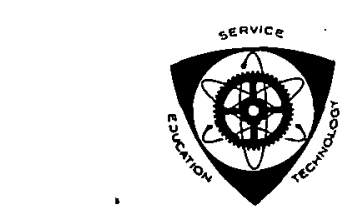

U. S. Atomic Energy Commission Research and Development Report Issued Under Contract AT(10-1)-1230 Idaho Operations Office 


\section{ACKNOWLEDGEMENTS}

The authors wish to acknowledge the assistance of Idaho Nuclear personnel and especially $\mathrm{Mr}$. G. A. Rigby who performed many of the hydrogen determinations required in this program. 
As a prerequisite to determining the combined effects of irradiation and hydrogen content upon the mechanical properties of ASTM A542, A302B and HY 80 pressure vessel steels the cathodically induced hydrogen occlusion was studied. The rate of occlusion increased with increasing current density, poison concentration (sodium arsenate or carbon disulfide) and irradiation. The induction period was reduced by increased current density and irradiation. Specimens were irradiated to $4 \times 10^{17} \mathrm{n} / \mathrm{cm}^{2} \mathrm{E}>1 \mathrm{MeV}$ and the radioactivity measured $2-3 \mathrm{r} / \mathrm{hr}$ at contact prior to testing. Increasing the poison concentration and irradiation also resulted in an increase in the apparent "supersaturation" solubility. The increased occlusion rates found with the irradiated specimens were attributed to either changes in the specific rate constants for absorptior and desorption or the number of surface active sites. The increased apparent solubility limit was attributed to increased hydrogen trapping. 
CONTENTS

ACKNOWLEDGEMENTS . • . . . . . . . . . . . . . . . . . . . . . . . . . . . ii

ABSTRACT . . . . . . . . . . . . . . . . . . . . . . . . . $i i i ~$

I. INTRODUCTION . . . . . . . . . . . . . . . . . . . . . . . . . . . 1

II. EXPERIMENTAL . . . . . . . . . . . . . . . . . . . . . . . . . . . . . . I

A. Techiniques . . . . . . . . . . . . . . . . . . . 1

B. Results . . . . . . . . . . . . . . . . . . . . 2

C. Limitations . . . . . . . . . . . . . . . . . . . . . T

III. DISCUSSTON

IV. ADIITIONAL WORK . . . . . . . . . . . . . . . . . . . . . . . . II

V. SUMMARY . . . . . . . . . . . . . . . . . . . . . . . . . . . . . I I

REFERENCES . . . . . . . . . . . . . . . . . . . . . . . . . . . 14

FIGURES

1. Gas Analyzer . . . . . . . . . . . . . . . . . . . . . . . . . 3

2. Effect of: Current Density on Hydrogen Content of Unirradiated ASTM

A542 Steel . . . . . . . . . . . . . . . . . . . . . . . . . . . . 4 4

3. Cathodié Hydrogenation of Pre \& Póst-Irradiated HY 80 steel at

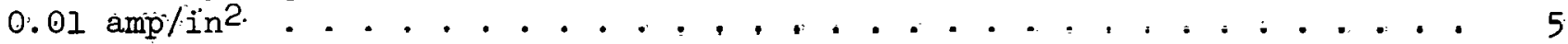

4. Cathodic Hydrogenation of Pre and Pnst-Trraniated HY 80 Steel . . . . . . . G

5. Permeability and Diffusivity Measurement . . . . . . . . . . . . . I2

\section{TABLES}

I.. Apparent Diffusivity of Irradiated and Unirradiated Samp:les . . . . . . . . . . . . 11 


\section{EFFECTS OF IRRADIATION ON THE SURFACE ACTIVITY AND}

\section{DIFFUSIVITY OF HYDROGEN IN STEELS*}

C. R. Brinkman and J. M. Beeston

\section{INTRODUCTION}

Pressure vessel steels are not normally susceptible to hydrogen embrittlement. It is the purpose of the program on hydrogen embrittlement of steels to determine whether upon irradiation the higher strength structural steels in their normal service condition are susceptible to hydrogen embrittlement, or whether they can be made susceptible by heat treatment (e.g., heat affected zone in weldments) or prestrain. The work reported is part of the preliminary investigations initiated ito evaluate the effects of hydrogen on the mechanical properties of ASTM A302B, A542 and HY 80 pressure vessel steels that are being irradiated to fluences of $10^{19}$ to $10^{21} \mathrm{n} / \mathrm{cm}^{2} \mathrm{E}>1 \mathrm{MeV}$. Samples of the steels have been irradiated or are in the process of being irradiated in the ETR, and will be tested by low strain rate tensile tests and by static load (stress rupture) tests to determine their susceptibility to hydrogen induced timedependent failure.

This report discusces part of the hydrogen charging methods and subsequent mechanisms of hydrogen entry into the samples. The variables examined and which affected the concentration of hydrogen in the samples were cathode charging current density, concentration of electrolyte poison, irradiation, and time. Although the effect of irradiation on the bulk properties (solubility and diffusivity) as distinct from the surface activity awaits to be accomplished in further testing, some of the relationships are examined in this presentation.

\section{EXPERIMENTAL}

A. Techniques - The technique of cathodic charging was selected as it affords a way of rapidly introducing quantities of hydrogen at room temperature into steels that would otherwise require high pressure hydrogen at elevated temperatures. Concentrations obtainable by thermal charging are reproducible; however, only relatively low concentrations are possible at temperatures and charging times that do not change the mechanical properties of the materials involved. Concentrations obtainable by cathodic churying are not as reproducible as those obtained thermally and have been shown to be sensitive to such parameters as specimen surface condition, current density, additives or poisons present in the electrolyte, specimen composition, heat treatment, and processing history.

Specimen blanks of $\mathrm{HY} 80 \mathrm{steel}$, i.e. $0.14 \mathrm{C}, 0.20 \mathrm{Mn}, 3.01 \mathrm{Ni}, 1.6 \mathrm{Cr}, 0.50 \mathrm{Mo}$, balance $\mathrm{Fe}$, in the quenched and tempered condition were cut from the one quarter sections of $3^{\prime \prime}$ plates of this steel and machined into rods $0.3^{\prime \prime}$ in diameter and approximately 1.7" long with the long axis in the rolling direction. Some of these specimens were then irradiated in the VH-2 facility of the MTR at the NRTS to a fluence of $4 \times 1017 \mathrm{n} / \mathrm{cm}^{2} \mathrm{E}>\mathrm{IMeV}$ and allowed to cool to $2-3 \mathrm{r} / \mathrm{hr}$ at contact. Pre- and

* Work performed under contract AT(10-1)-1230 to the Atomic Energy Commission. 
post-irradiated specimens were then hydrogen charged by making them the cathode in a cell containing $4 \% \mathrm{H}_{2} \mathrm{SO}_{4}$ with varying amounts of sodium arsenate or carbon disulfide added to serve as a poison. Platinum foil served as the anode. Specimens were charged at different current densities for various times at laboratory ambient temperatures. After charging the specimens where stored in liquid nitrogen until they were analyzed for hydrogen.

The analyses were made on an EA-l Exhalograph Gas Analyzer ${ }^{1}$, an analyzer capable of determining quantitatively bxygen, nitrogen, and the hydrogen concentration down to $0.05 \mathrm{ppm}$. A photograph of this analyzer is shown in Figure 1. Standard Bureau of Standards hydrogen samples were used for calibration and verification of the capabilities of the equipment. A sample of titanium specified at $0.003 \%$ hydrogen analyzed $31.9 \pm 0.75 \mathrm{ppm}$ by weight hydrogen. Another sample specified at $0.01 \%$ hydrogen, analyzed $95.2 \pm 0.4 \mathrm{ppm}$ by weight hydrogen.

Hydrogen determinations are automatic and require about three minutes (time is dependent upon sample size and extraction temperature). The sample was introduced through a vacuum l'ock and the gas hot-extracted at $1,000^{\circ} \mathrm{C}$ from the specimen. Automatic determination of the hydrogen present was made by a thermal conductivity measurement.

As has been reported by other investigators ${ }^{2}$ a linear relalionship exists between hydrogen content and the square root of charging time up to a saturation concentration (actually supersaturation concentration) of hydrogen.

B. Results - The effect of an increase in cathode charging current density was to increase the concentration of hydrogen in the sample especially before saturation reportedly ${ }^{3}$ associated with increasing hydrogen surface coverage. This effect at current densities between 0.001 and $0.1 \mathrm{amp} / \mathrm{in}^{2}$ was slightly more pronounced with carbon disulfide a's a poison, Figure 2, than with sodium arsenate, Figure 3. There was, however, a much greater change from a current density of 0.001 to 0.01 amp/in ${ }^{2}$ in Figure 2 than from 0.01 to $0.1 \mathrm{amp} / \mathrm{in}^{2}$, wherein the slope of the curves was essentially the same. The differences between current densities of 0.01 and 0.1 amp/in ${ }^{2}$ in Figure 3 for the unirradiated samples was even les pronounced, but that of the irradiated apparently widens as if a greater number of surface det.ive adsorptiun sites were available.

An increasing concentration from 3 to $34 \mathrm{mg} \mathrm{As} / \mathrm{l}$ of sodium arsenate as cathode electrolyte poison increases the rate of hydrogen occlusion, Figure 4, Part A. Irradiation also as seen in Parts $B$ through $D$ increases the rate of hydrogen occlusion. Not only does the rate of hydrogen occlusion in irradiated samples increase, but so also does the saturation solubility. The effect of irradiation appears to be additive to that of the sodium arsenate concentration.

The initial non-linear portions (induction periods) of the curves is thought to be due to a time lag required for the establishment of the eloctrical double layer at the metal sulution interface. The induction period decreases for increased current density and for irradiated samples.

Sodium arsenute is considered a better poison for our purposes, since it is easier to clean from the sample surface.

Increased arsenic concentration from 3.4 to $33.6 \mathrm{mg}$ As/liter increased the rate of occlusion of hydrogen in both the irradiated and unirradiated samples. Arsenic like some of the other elements of the periodic groups, V and VI, acts as a "negative catalyst" which is believed ${ }^{4}$ to impede the hydrogen recombination reaction. 


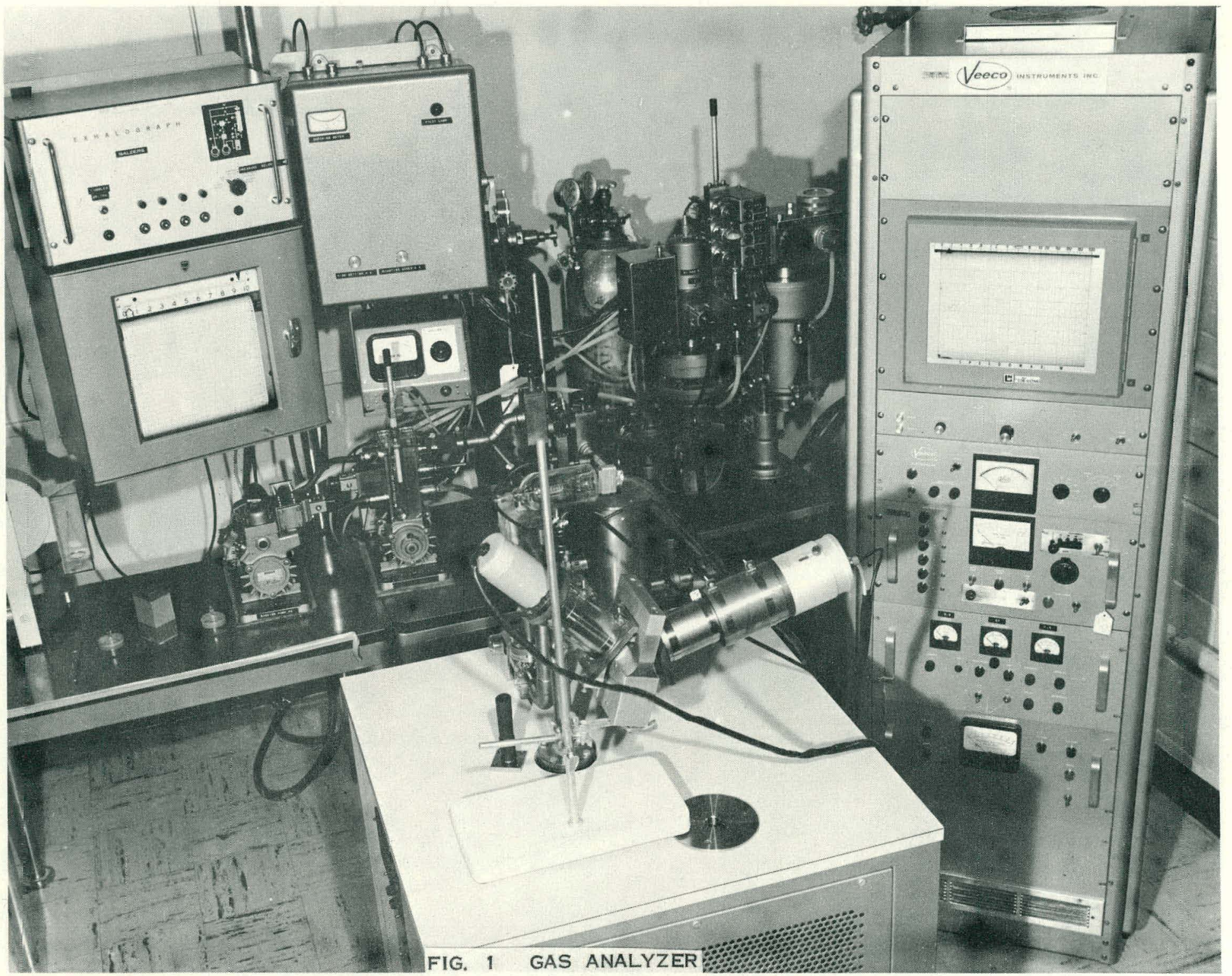




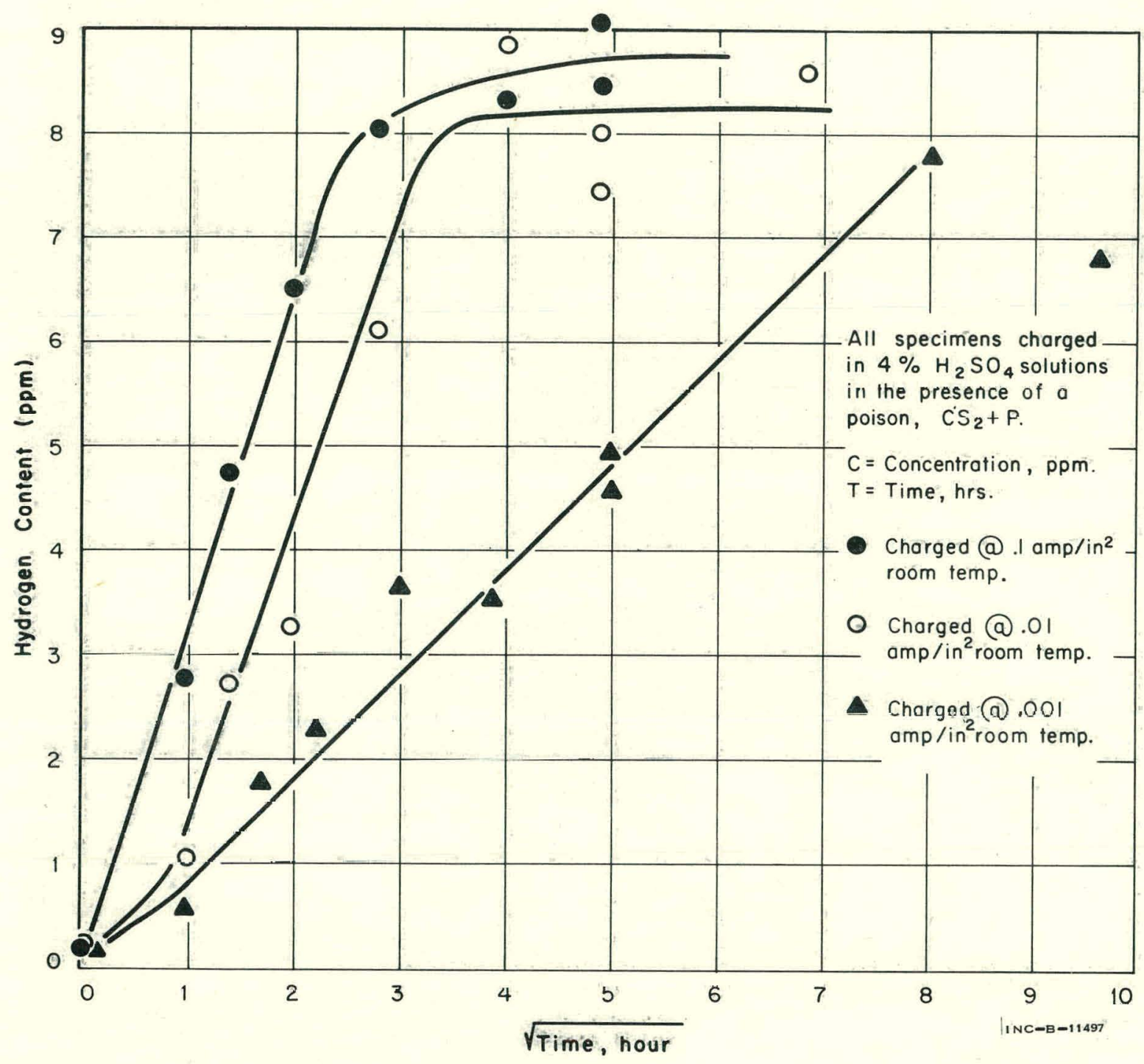

Figure -2

Effect of Current Density on Hydrogen Content

of Unirradiated ASTM A542 Steel 


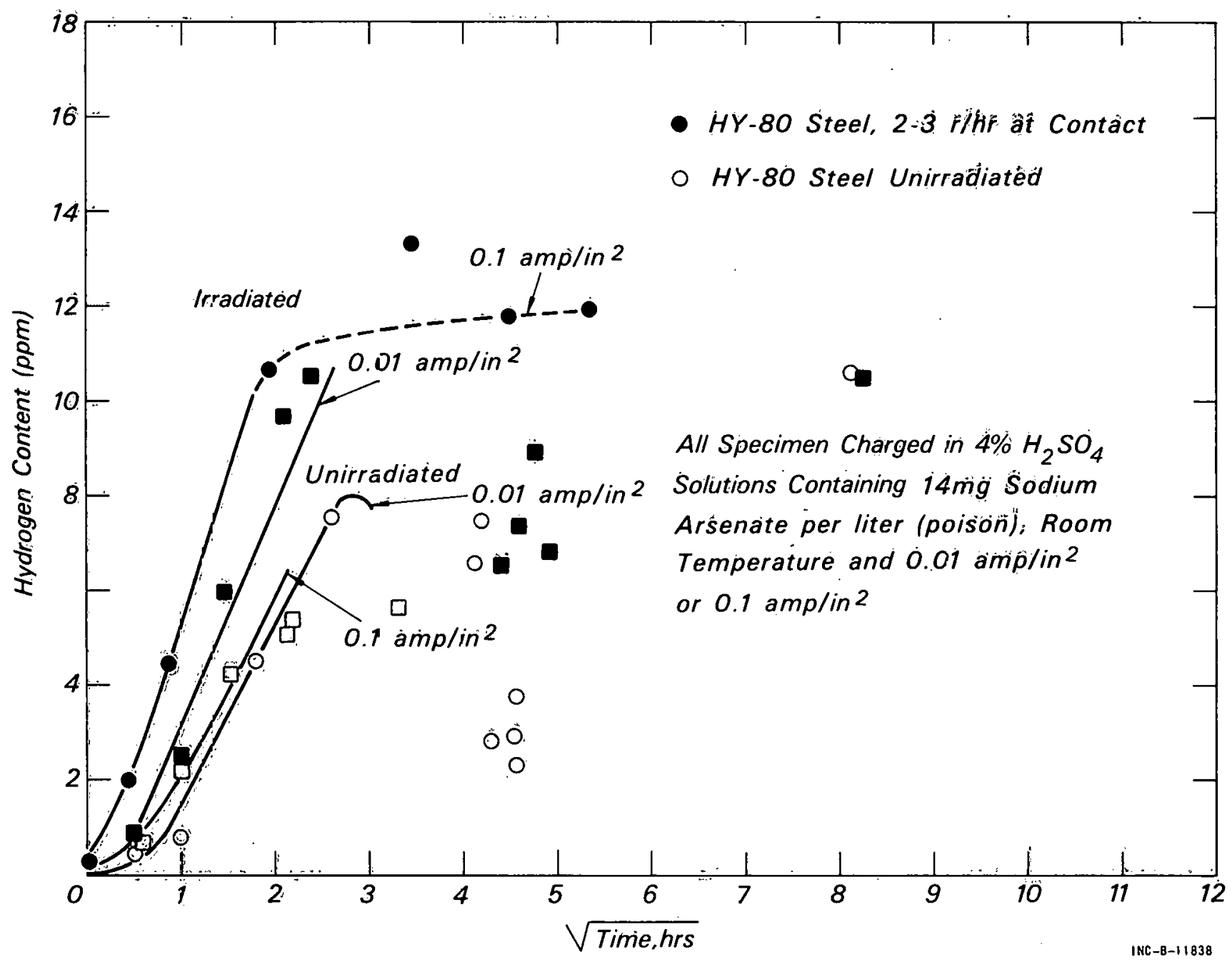

Figure 3

Cathodic hydrogenation of pre \& post irradiated HY-80 steel at 0.01 amplin ${ }^{2}$ and $0.1 \mathrm{amp} / \mathrm{in} \cdot 2$ 


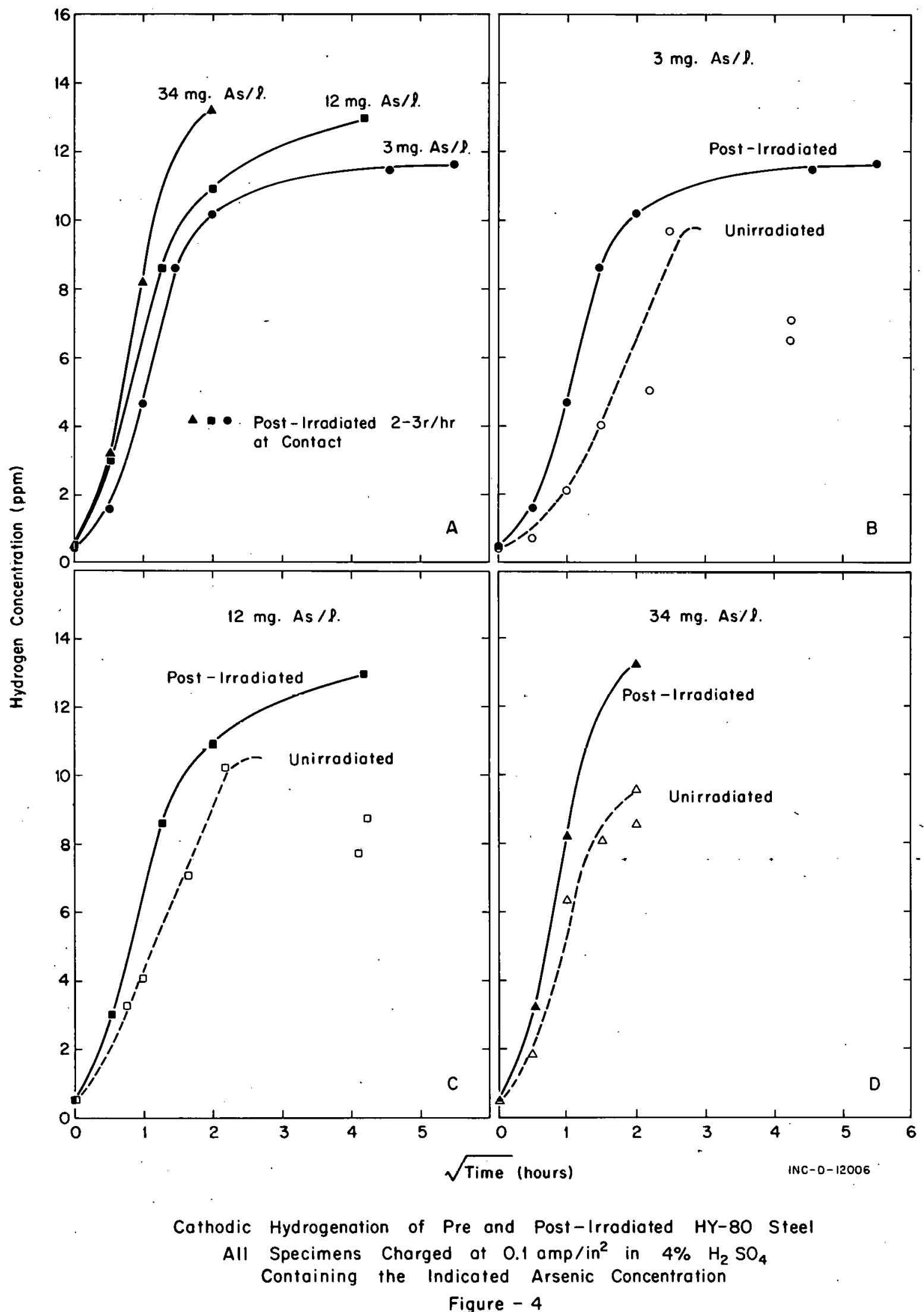

$-6-$ 
It has been reported ${ }^{5}$ for pickling solutions that in $2 \mathrm{~N}$ sulfuric acid arsenic in excess of $8 \mathrm{mg} /$ liter inhibits the hydrogen absorption. No evidence of this has been found in the cathodic charging performed to date.

C. Limitations - For many of the curves, scatter in the data in the slope of the curves produces too great an uncertainty to calculate a diffusivity from the slope. A further difficulty in using the slope and the non-steady state solution of Fick's second law to compute the diffusivity is that there is a hydrogen gradient through the sample and the diffusion length cannot be related to a known concentration. An apparent diffusivity will be calculated as given in the discussion section from the non-steady state solution at saturation. It is noted also that the data taken after the supersaturation is reached are not reproducible especially with arsenic as poison. This irreproducibility may be the result of some of the following three effects :

1. Depletion of the arsenic which has been reported ${ }^{6}$ to form a hydride and be evolved from solution.

2. A decrease in current density caused by an increase in the surface area as a result of blistering and cracking of the surface after saturation.

3. Variation of cell contact potentials which vary the applied overpotential.

\section{DISCUSSION}

As presented in the previous section irradiated samples exhibited a decreased time lag (induction period) for establishment of the electrical double: layer, increased rate of hydrogen occlusion, and an increased saturation solubility. These effects are due to increased surface or solution activity, or to changes in bulk properties (diffusivity and solubility). However, the induction period is entirely due to surface or solution activity changes. It is generally accepted ${ }^{7}$ that trapping reduces hydrogen diffusivity and leads to high solubility at temperatures less than approximately $400^{\circ} \mathrm{C}$. The partial similarity of the effect of irradiation to that of increased current density, and increased electrolyte poison which are surface reaction effects indicates also that a surface activity effect may be influencing the rate of hydrogen occlusion.

The nature of this effect is investigated by a consideration of permeability steps involved. These are indicated with the probable reactions. The effect will then be linked to a change in the activation energy of some process (formation of molecular hydrogen, passage of atomic hydrogen through the metal surface, etc.) and thus changing the reaction rate constant. or the number of surface active sites for hydrogen absorption. The reaction steps involved in the heterogeneous processes are as follows:

1. Diffusion of proton-bearing species from the bulk solution to cathode or double layer.

(This step is probably very fast due to the high hydrogen ion concentration, i.e. $1.4 \mathrm{~N} \mathrm{H}_{2} \mathrm{SU}_{4} \cdot$ )

2. Adsorption of hydrogen atoms at the cathode surface.

3. Competitive reactions between formation of molecular hydrogen at the cathode surface and absorption of hydrogen into the bulk of the specimen.

These reactions can be expressed as follows: 


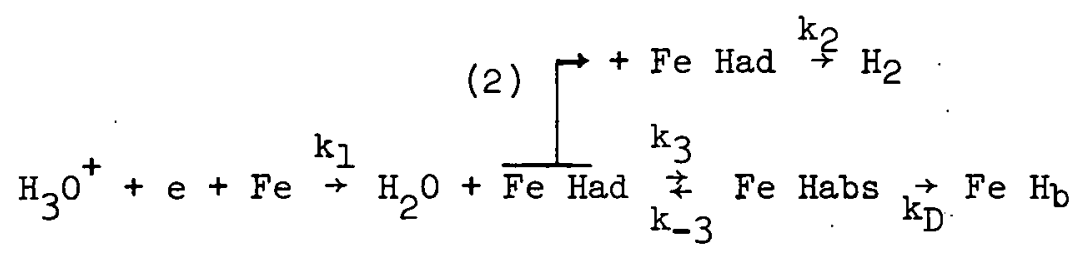

(4)

where $\mathrm{k}_{3}$ = specific rate constant for reaction (3) in forward direction.

$\mathrm{k}_{-3}=$ specific rate constant for reaction. (3) in backward direction.

$\mathrm{C}_{\mathrm{S}}=$ concentration of hydrogen in bulk material just under the surface.

$\mathrm{k}_{\mathrm{D}}=$ specific rate constant for flow of hydrogen from the surface layer into the specimen bulk.

Had = hydrogen on the surface .sites.

Habs = hydrogen in the material near the surface.

$\mathrm{k}_{\odot}=$ number of active surface sides.

$\mathrm{H}_{\mathrm{b}}=$ hydrogen in the bulk material.

As has been pointed out by Barton' ${ }^{8}$ reaction (1) may be fast or slow with reaction (2) just the opposite depending upon the hydrogen overvoltage and the current density. As was mentioned previously it is believed that arsenic impedes hydrogen recombination, reaction (2).

Many investigators (Bockris, et al ${ }^{9}$, F. deKazinczy ${ }^{19}$ ) have reported that for the case of cathodic charging diffusion in the bulk material is the rate controlling step and not the rate of the surface reactions. Hydrogen penetrates the surface and rapidly builds up a concentration in subsurface layers (M. Lasocka and W. Racynskill, H. H. Johnson, et $\mathrm{al}^{12}$ ) and then diffuses into the bulk of the material. A summary of the assumptions inherent in the following solution for the concentration $\left(C_{s}\right)$ of hydrogen in the bulk steel just under the surface is as follows:

1. Solution concentration gradients are negligible (solution diffusion not limiting).

2. Adsorption of hydrogen atoms at the surface is fast (reaction 1). A condition consistent with the higher current density and irradiation.

3. A hydrogen concentration limit is reached corresponding to the solubility limit for the specific charging conditions.

The rate of change of the surface concentration $C_{s}$ can then be expressed as:

$$
\frac{d C_{s}}{d t}=k_{0} k_{3}\left[a_{H}\right]_{a d}-k_{-3} C_{s}^{2}-C_{s} k_{D}
$$

In the first term the adsorption of hydrogen is considered to follow first-order kinetics, which was shown ${ }^{1} 3^{\circ}$ to be the usual case at low temperatures. $C_{S}$ is squared in the above expression since for. specimen outgassing, desorption in an aqueous environment follows second order kinetics (R. M. Hudson, et al ${ }^{14}$ ). That is, the overall desorption reaction should he expressed as:

$$
2 \mathrm{H}_{\text {abs }} \stackrel{\mathrm{k}}{\rightarrow} \mathrm{H}_{2}
$$

It was shown that hydrogen gas was weakly adsorbed so that the rate constant for the overall reaction $k$ was equivalent to the rate constants for the back reactions (3) and (2). 
The value of $\left[a_{\mathrm{H}}\right]$ ad or the surface coverage depends upon the rates of reactions (1), (2) and (3). At the steady state $\frac{d C_{S}}{d t}=0$ and

$$
c_{S}=\frac{k_{D}}{k_{-3}} \pm \sqrt{\left(\frac{k_{D}}{k_{-3}}\right)^{2}+4\left(\frac{k_{3} k_{0}}{k_{-3}}\right)^{a_{H}}}
$$

After long times, i.e. 1 to 4 hours, the concentration of the bulk approaches that of the surface, and thus, the experimental hydrogen concentration'; $G_{\dot{s}}$, with increasing time. It is apparent from the experimental data that irradiation increases not only this steady state concentration or solubility but also the rate of approach to it. A similar effect was observed to occur in unirradiated steels with increasing amounts of cold work, by R. M.. Hudson and G. L. Stragand ${ }^{15}$..

Let us now consider the meaning of equation. (7) in terms of the effect of irradiation on the increased rate of hydrogen occlusion or of surface activity. If the rate constant for the absorbed hydrogen diffusing in the bulk steel, $\mathrm{k}_{\mathrm{D}}$; is much smalier than the rate constant, $k_{-3}$, for the absorbed hydrogen going to the adsorbed state, i.e. $\mathrm{k}_{\mathrm{D}}^{\mathrm{i}} \ll \mathrm{k}_{-3}$, then,

$$
c_{s} \approx 2\left(\frac{k_{3} k_{0}}{k_{-3}}\right)^{1 / 2}\left(a_{H}\right)^{1 / 2}
$$

In absolute reaction rate theory the rate constant, $k$, is a function of the transmission coefficient, $K$, which gives the fraction of activated complexes that pass over the energy barrier, $E_{O}$, and the partition functions, $F$, for the activated complex and reacting species. Since arsenic apparently inhibits hydrogen recombination (equation. 2), it effectively increases the activity of the hydrogen adsorbed, $a_{H}$.

In considering the effect of irradiation on the surface reactions and thus on the rate of occlusion, we are led to changes in the rate constants or numbers of surface active sites as the most likely of several possibilities as follows:

1. Radiolysis of water and an increase in the amount of adsorbed hydrogen by the overall reactions:

$$
\begin{aligned}
& \mathrm{H}_{2} \underset{\beta}{\stackrel{\gamma}{\longrightarrow}} 2 \mathrm{H}_{\text {ads }} \\
& \text { or } \\
& \mathrm{H}_{2} \Theta^{\prime}+\underbrace{\gamma}_{\beta} \mathrm{H}+\mathrm{OH}
\end{aligned}
$$

could occuirl't

However, since the solution is very acidic extensive amounts of radiolytic decomposition will be opposed by the high hydrogen ion concentration and therefore the effects of radiolytic decomposition should be negligible.

2. Now with respect to changes in the rate constant, or an increase in the number of 'urface active sites. Calculations'l based on absoliute rate theory have indicatea

lat in the case of 'smooth metal surfaces the fraction of most active sites irs large. While in the case of oxides and composite catalysts the active sites may comprise only a thousandith or less of the total number. The exact nature of the surfaces of the specimens u'sed are not known but the surface was no doubt covered by an oxide film at least several atomic diameters thick due to exposure to an aqueous environment 
during and after irradiation. Several different types of active absorption sites might also be involved in the overall absorption process; for instance, one site that favors the adsorption step and another in combination with the first that favors transfer of the adsorbed hydrogen into the metal surface, if indeed several different sites are involved. Thus, there would be variation of site activity over the surface brought about by irradiation induced activation. The overall rate, then, is the sum of the rates on the various types of sites and the absolute rate constant becomes

$$
\mathrm{k}_{3}=\mathrm{C}_{\text {Hads }} \frac{\mathrm{KkT}}{\mathrm{h}} \frac{1}{\mathrm{~F}_{\text {Hads }}} \sum_{i} \mathrm{C}_{i} \mathrm{e}^{-\mathrm{E} \mathrm{i} / \mathrm{RT}}
$$

where: $C_{\text {Hads }}=$ Concentration of adsorbed hydrogen.

$\mathrm{K}=$ Transmission coefficient

$\mathrm{k} \quad=$ Planck's constant.

$\mathrm{h} \quad=$ Boltzman's constant

$\mathrm{F} \quad$ = Partition function for adsorbed hydrogen.

$\mathrm{C}_{i}=$ Concentration of a particular surface site active in the absorption process.

$\mathrm{E}_{\mathrm{i}} \quad$ = Activation energy for absorption on ith site.

$\mathrm{R}, \mathrm{T}=$ Gas constant and temperature.

If the reaction occurs mainly on the most active sites then the energy of activation of the overall process will decrease and approach the value which corresponds to these sites.

Summarizing, there are at least two possibilities: First, that absorption of hydrogen occurs on a single type of active surface site and that irradiation increases the total number or fraction $\mathrm{k}_{\mathrm{O}}$ of the total surface sites, and second, that irradiation creates a new unique active site which results in a decrease in the overall activation energy for absorption and hence an increase in the overall rate. For simplification only a single active site was assumed for $k_{3}$ in equation (5).

3. A decrease in the rate of desorption as expressed in reaction (6). This could be brought about by an irradiation induced increase in the surface solubility, as a result of an increased number of hydrogen trapping sites or due to a dccrease in the number of active surface sites utilized during desorption. At the fluence level $\left(4 \times 10^{17} \mathrm{n} / \mathrm{cm}^{2}\right)$ and temperature, $100^{\circ} \mathrm{C}$, of irradiation the effect of increasing the rumber of trapping sites was expected to be small. However, the calculations of the apparent diffusivity indicated a decreased diffusivity of the irradiated samples. Additional measurements of diffusivity and solubility are expected to elucidate this question.

Of the several effects of irradiation discussed. above changes in rate constant or numbers of active sites seem the most likely. Determination of which mechanism, i.e. absorption or desorption is the most affected would require additional experimentation, e.g. a desorption study.

If the rates of the surface reactions are fast compared with transfer of hydrogen within the bulk of the metal as postulated above ( $\mathrm{kD} \ll \mathrm{k}$ surface) then the apparent diffusion constants can be calculated using the supersaturation solubility and a non-steady state solution of Fick's Second Law. Penetration curves 18 are given which plot $\frac{C_{m}}{C_{s}}$ vs. $\frac{\sqrt{D t}}{R}$ where $C_{m}$ is the mean concentration at time $t, C_{S}$ is the constant surface 
concentration approached, $D$ is the diffusivity and $R$ is the specimen radius in centimeters. If the time required for $C_{m}$ to equal $C_{S}$ is used then for a cylindrical specimen,

$=R^{2} / t_{S}$, where $t_{S}$ is equal to the saturation time. Several values of the diffusivity of hydrogen in plain and irradiated HY 80 steel have been calculated, Table I, for charging conditions where $\mathrm{C}_{S}$ is clearly indicated or found by extrapolation.

Table I

Apparent Diffusivity of Irradiated and Unirradiated Samples

\begin{tabular}{|c|c|c|c|c|}
\hline Current Density & $\begin{array}{l}\text { Arsenic } \\
\text { Conc. }\end{array}$ & $\mathrm{C}_{\mathrm{s}}(\mathrm{ppm})$ & Irradiated & D $\mathrm{cm}^{2} / \mathrm{sec}$ \\
\hline $.01 \mathrm{amp} / \mathrm{in}^{2}$ & $3 \mathrm{mg} / \mathrm{I}$ & 13.25 & Yes & $4.4 \times 10^{-6}$ \\
\hline $.01 \mathrm{amp} / \mathrm{in}^{2}$ & $3 \mathrm{mg} / \mathrm{I}$ & 7.5 & No & $6 \times 10^{-6}$ \\
\hline $.1 \mathrm{amp} / \mathrm{in}^{2}$ & $3 \mathrm{mg} / \mathrm{I}$ & 11.5 & Yes & $1.33 \times 10^{-6}$ \\
\hline . I amp/in 2 & 3. $\mathrm{mg} / \mathrm{l}$ & 9.6 & No & $6.4 \times 10^{-6}$ \\
\hline . I amp/in 2 & $12 \mathrm{mg} / \mathrm{l}$ & 13.0 & Yes & $2.2 \times 10^{-6}$ \\
\hline . $1 \mathrm{amp} / \mathrm{in}^{2}$ & $12 \mathrm{mg} / \mathrm{I}$ & 10.2 & No & $8.3 \times 10^{-6}$ \\
\hline
\end{tabular}

The calculated values of the diffusivity $D$ agree well with those obtained in the literature ${ }^{19}$, i.e. $10^{-5}-10^{-9}$ at $25^{\circ} \mathrm{C}$. The value at $25^{\circ} \mathrm{C}$ is not well defined as yet because of a trapping mechanism which is believed to be important at temperatures less than $400^{\circ} \mathrm{C}$. As the data indicates irradiation appears to decrease the diffusivity.

\section{A.DDITIONAL WORK}

Two additional tests as well as mechanical property measurements to further elucidat the effects of irradiation on the mechanisms of hydrogen absorption from aqueous environments and on the diffusion behavior of hydrogen in these steels are expected. Tubelike specimens with one end sealed will be irradiated and immersed in acid solutions and cathodically charged, Figure 5. Hydrogen diffusing into the tube will be pumped to a mass spectrometer and measured. The second test designed to measure the permeability of hydrogen through irradiated steel will also be conducted using tube-like specimens. The specimens will be irradiated to fluences of from $10^{19}$ to $10^{21} \mathrm{n} / \mathrm{cm}^{2} \mathrm{E}>1 \mathrm{MeV}$ and filled with hydrogen to several different pressures. The temperature over the gauge section wil be varieal from room temperature to approximately $300^{\circ} \mathrm{C}$ as this temperature region includes the interval over which the diffusion characteristics of hydrogen are not well defined.

The values of the hydrogen diffusivities will be calculated by the time-lag technique and the values compared for both tests.

\section{SUMMARY}

Increases in the cathode charging current density and the concentration of electrolytic solution poison, as well as irradiation, have been found to increase the rate of hydrogen occlusion and the supersaturation solubility. 


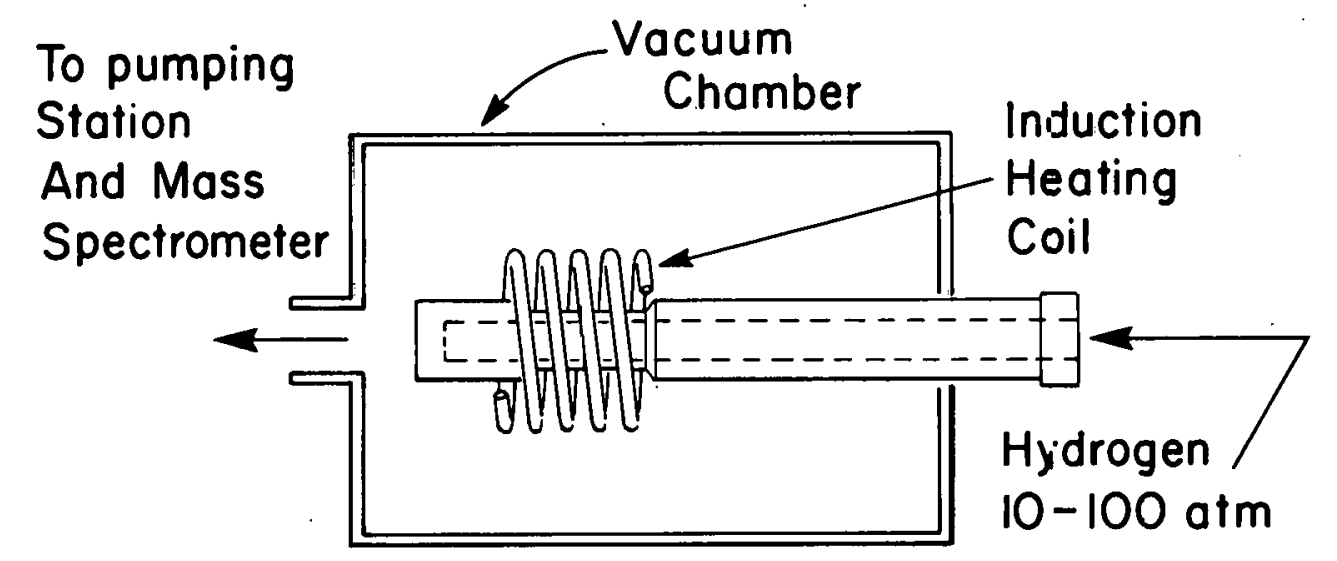

Figure 5
A. Test Conditions

I. Fluence: $10^{17}-10^{19} \mathrm{n} / \mathrm{cm}^{2}$ E $>1 \mathrm{MeV}$

2. Temperature: $25-80^{\circ} \mathrm{C}$

3. Experimental Data

a. Diffusivities

b. Permeabilities

B. Test Conditions

I. Fluence: $10^{19}-10^{21} \mathrm{n} / \mathrm{cm}^{2} \quad \mathrm{E}>1 \mathrm{MeV}$

2. Temperature: $25-300^{\circ} \mathrm{C}$

3. Pressure: $10-100 \mathrm{~atm}$

4. Experimental Data

a. Diffusivities

b. Permeabilities

INC-B-12032

Permeability And Diffusivity Measurement 
The increase in the rate of hydrogen occlusion in the irradiated samples is due ') decreased surface coverage lag time, and also thought to be due to increased surface :tivity during electrolytic charging, specifically to an increase in the number of surface active sites or changes in the rate constants.

The increased supersaturation solubility may be due to an increase in trapping of hydrogen, since an apparent diffusivity decrease in the irradiated samples was calculated. These are consistent effects reported in the literature for hydrogen trapping.

Additional measurements of the solubility and diffusivity of irradiated specimens, as well as mechanical property measurements, are planned, which will further define the behavior of hydrogen. in irradiated steel. 
G. Ramsey, 0. Winkler and T. Kraus, "A New Instrument for Determination of Gas Content in Metals", DMIC 200, Battelle Memorial Institute, March 11, 1964.

A. E. Schuetz and W. D. Roberston, "Hydrogen Absorption, Fmbrittlement and Fracture of Steel", Corrosion, Vol. 13, July 1957, p. $437 t$.

R. J. Barton, "The Mechanism of Transport of Hydrogen Across a Solution - Metal Interface", found in Hydrogen Embrittlement in Metal Finishing, by H. J. Read, Reinhold Publishing Corporation, New York, New York, 1961, p. 37.

M. Smialowski, Hydrogen in Steel, Pergamon Press, New York, New York, 1962, p. 109.

R. M. Hudson and G. L. Stragand, "Influence of Arsenic on Pickling of and Hydrogen Absorption by Mild Steel in Sulfuric Acid Solutions", Corrosion, Vol. 18, 1962 , p. 259 t.

M. Smialowski, Hydrogen in Steel, Pergamon Press, New York, New York, 1962, p. 110.

K. Ono and L. A. Rosales, "On the Anomalous Behavior of Hydrogen in Iron at Lower Temperatures", AIME Trans., Vol. 242, February 1968, p. 244.

R. J. Barton, "The Mechanism of Transport of Hydrogen Across a Solution - Metal Interface" found in Hydrogen Embrittlement in Metal Finishing, H. J. Read, Reinhold Publishing Corporation, 1961, p. 20

J. O'M. Bockris, J. McBreen and L. Nanis, "The Hydrogen Evaluation Kinetics and Hydrogen Entry into a Iron", J. Electrochemical Society, Vol. 112 \#10, p. 1027.

F. deKazinczy, "Hydrogen Occlusion and Equilibrium Hydrogen Pressure in Steel During Electrolytic Charging", Jern Kontorets Annaler ARG., 139 (1955) 7, p. 467.

il M. Lasocka and W. Racznyski, "Diffusion, Permeation, and Absorption of Cathodic Hydrogen in Ferritic Chromium Steel", Bulletin De L'Academic Polonaise Des Sciences, Vol. XV, \#1, 1967, p. 33.

H. H. Johnson, J. G. Morlet, A. R. Troiano, "Hydrogen Crack Initiation and Delayed Failure in Steel", AIME Trans., August 1958, p. 582.

K. J. Laidler, Chemical Kinetics, McGraw-Hill, New York, New York, 1965, p. 284.

R. M. Hudson, K. J. Riedy and G. L. Stragand, "Influence of Specimen Geometry and Surface Roughness on Hydrogen Behavior in Steel", Corrosion, Vol. 18, 1962, p. $79 t$.

R. M. Hudson and G. L. Stragand, "Effect of Cold Drawing on Hydrogen Behavior in Steel", Corrosion, Vol. 16,'1960, p. 253t.

D. R. Harries, C. H. Broomfield, "Hydrogen Embrittlement of Steel Pressure Vessels in Pressurized Water Reactor Systems", J. Nucl. Met., 9, \#3, p. 327, (1963).

K. J. Laidler, Chemical Kinetics, McGraw-Hill, New York, New York, 1965, p. 302.

18 L. S. Darken, R. W. Gurry, Physical Chemistry of Metals, McGraw-Hill, New York, New York, 1953, p. 446.

19 M. L. Hill, "The Behavior of Hydrogen in Iron and Steel", Hydrogen Embrittlement in Metal Finishing, H. J. Read, Reinhold Publishing, 1961, p. 57 . 